\title{
Application of combined-type Y-shaped covered metallic stents for the treatment of gastrotracheal fistulas and gastrobronchial fistulas
}

\author{
Teng-Fei Li, MD, ${ }^{\mathrm{a}, \mathrm{b}}$ Xu-Hua Duan, MD, ${ }^{\mathrm{a}, \mathrm{b}}$ Xin-Wei Han, MD, ${ }^{\mathrm{a}, \mathrm{b}}$ Gang Wu, MD, ${ }^{\mathrm{a}, \mathrm{b}}$ \\ Jian-Zhuang Ren, MD, ${ }^{\mathrm{a}, \mathrm{b}}$ Ke-Wei Ren, MD, ${ }^{\mathrm{a}, \mathrm{b}}$ and Hui-Bin Lu, MD ${ }^{\mathrm{a}, \mathrm{b}}$
}

\section{ABSTRACT}

Objective: To determine the safety and feasibility of combined-type integrated Y-shaped self-expanding covered metallic stents to treat gastrotracheal fistulas (GTFs) and gastrobronchial fistulas (GBFs).

Methods: We retrospectively reviewed the data of 10 patients with postoperative GTFs or GBFs. Depending on the size and location of the fistula and the airway diameter, we custom-designed 2 or 3 stents for each patient. The combined-type stents consisted of a large and a small Y-shaped stent. Under fluoroscopic guidance, the small stent was inserted into the distal part of the involved airway. Then, the large stent was placed at the trachea and carina. The large stent partly overlapped the main body of the small stent.

Results: All stents were successfully inserted at the first attempt. Esophageal and airway radiography showed no contrast agent leakage, indicating that the fistula was fully sealed. After the procedure, the patients could resume eating without coughing, and their quality of life improved. Each patient was fully followed up. Six patients died at 3.2 to 8 months of tumors (4 patients), hemoptysis (1 patient), or pulmonary infection (1 patient). In 1 patient, the carinal fistula enlarged 4 months after stenting, and another small Y-shaped stent was inserted to seal the fistula. This patient and the remaining 3 patients are still alive.

Conclusions: Deployment of the combined-type Y-shaped integrated selfexpanding covered metallic stent proved to be an effective, safe, and minimally invasive procedure for complex GTFs and GBFs. Our patients tolerated the stents well and had good palliation of their symptoms. (J Thorac Cardiovasc Surg 2016;152:557-63)

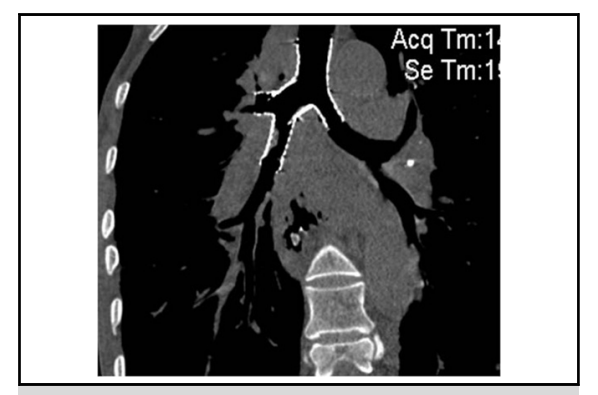

The treatment of a patient with GBF (1 small Y-stent and 1 large $Y$-stent inserted)

\section{Central Message}

The placement of combined-type Y-shaped self-expandable coated metallic stents is a new method for the treatment of GTFs and GBFs.

\section{Perspective}

Single and combined tubular stents have been used to treat GTFs and GBFs, but the rates of leakage and stent dislocation were high. The placement of combined-type Y-shaped fully covered self-expandable metallic stents is clinically feasible, and the short-term curative effects were reliable, suggesting that this could be a new method for the treatment of GTFs and GBFs.

See Editorial Commentary page 564.

See Editorial page 317.
From a Department of Interventional Radiology, the First Affiliated Hospital of Zhengzhou University; and ${ }^{\mathrm{b}}$ Interventional Institute of Zhengzhou University, Zhengzhou, P.R. China.

This study was supported by the National High-tech R\&D Program of China (863 Program) (number 2015AA020301).

Received for publication Sept 18, 2015; revisions received Dec 19, 2015; accepted for publication March 13, 2016; available ahead of print May 7, 2016.

Address for reprints: Xin-Wei Han, MD, Department of Interventional Radiology, the First Affiliated Hospital of Zhengzhou University, Zhengzhou 450052, P.R. China (E-mail: xinwei_han@163.com).

$0022-5223 / \$ 36.00$

Copyright (c) 2016 by The American Association for Thoracic Surgery

http://dx.doi.org/10.1016/j.jtcvs.2016.03.090
Gastrotracheal fistula (GTF) and gastrobronchial fistula (GBF) are extremely rare and life-threatening complications of esophagectomy. ${ }^{1-4}$ The formation of fistulas

Scanning this QR code will take you to the article title page.

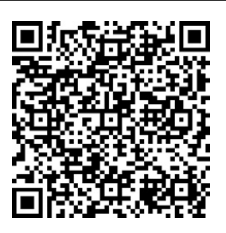




\section{Abbreviations and Acronyms \\ $\mathrm{GTF}=$ gastrotracheal fistula \\ $\mathrm{GBF}=$ gastrobronchial fistula \\ $\mathrm{SCT}=$ spiral computed tomography}

between the tracheobronchial tree and the stomach in the late postoperative period after gastric pull-up surgery is most often caused by tumor recurrence, radiation necrosis, and tracheobronchial erosion along the gastric staple line..$^{5-7}$ A covered metallic esophageal stent would be the first choice for the management of GTFs and GBFs, but most often the clinician faces a situation in which the esophageal stent should have a larger diameter on the gastric side making stenting the alimentary side of the fistula insufficient. ${ }^{5}$ Moreover, the risk of migration is high for stents placed in the gastric pull-up segment. ${ }^{5}$ Some investigators have used single or combined covered tubular airway stents to treat GTFs and GBFs, but the bifurcated structure of the trachea and main bronchi causes a rate of $5.7 \%$ to $57 \%$ of leakage and stent displacement. $^{1,8-11}$ Y-shaped self-expanding covered metallic stents have been used for sealing fistulas of the airway, with good outcomes. ${ }^{4,12}$ However, in the case of large GTFs and GBFs, and fistulas that involve the carina or the left or right main bronchus, a single Y-shaped stent might not fully seal the fistula. In this study, we used the combined-type Y-shaped covered metallic stent to treat large GTFs and GBFs and fistulas that involved the carina or the left or right main bronchus in 10 patients. The procedure of stent implantation and the recommendations for its use are discussed. The primary aim of our study was to determine the feasibility and safety of this technique for the treatment of complex GTFs and GBFs. A secondary aim was to calculate the long-term stent patency and complication rates during follow-up.

\section{METHODS}

Our institutional review board approved this retrospective study, and written informed consent was obtained from each participant or their next of kin for the use of their clinical records in this study.

\section{Patients}

From January 2010 to January 2014, we treated 10 patients who had developed complex GTFs or GBFs after undergoing esophagectomy for the treatment of esophageal cancer. Their clinical and imaging data were retrospectively analyzed, and are summarized in Table 1, and nutritional parameters were assessed using Nutritional Risk Screening 2002. ${ }^{13-15}$ In all patients, the diagnosis was made using spiral computed tomography (SCT) of the chest and bronchoscopy. All patients had undergone esophageal cancer resection and supra-aortic arch gastroesophageal anastomosis 6 to 17 months before the intervention. Of the 10 study patients, 9 had undergone radiotherapy (6000-7000 cGy) for the original esophageal cancer, and in these patients, the fistula appeared 5 to 16 months after radiotherapy. The remaining patient had undergone radiotherapy (6500 cGy) 2 months before surgery and received chemotherapy (with 5-fluorouracil, cisplatin, etc.) for 3 months after surgery. In this patient, the fistula appeared 9 months after radiotherapy ( 4 months after chemotherapy). All patients coughed when drinking or eating, and these symptoms were aggravated when the patients were lying down. Two patients had fever and hemoptysis. The patients had undergone antiinflammatory drug treatment, gastrointestinal decompression, and enteral nutrition for 7 days to 5 months before the stenting, with poor results.

\section{Preintervention Preparation}

Before the intervention, all patients had varying levels of malnutrition. Once the fistula was diagnosed, an intestinal feeding tube was inserted using digital subtraction angiography or endoscopy. Enteral nutrient solution (produced by the general nutrition center of our hospital), together with intravenous hyperalimentation, was injected through the tube to maintain caloric intake 3 to 5 days before the stent was manufactured. The enteral nutrient solution was used for 1 to 2 weeks (or longer in some weak patients) after stenting while oral intake was gradually recovered. Routine blood tests, including liver and renal function, blood coagulation function tests, and pulmonary function tests were also performed before the procedure. Chest SCT and bronchoscopy were used to determine the location and size of the fistula. The inner diameter of the trachea and bronchi were measured using chest SCT, and large (placed across the carina) and small (placed across the bifurcation of the lobar bronchus) Y-shaped stents were customized for each patient according to the imaging data.

TABLE 1. Clinical data of the 10 patients with complex gastrotracheal fistulas and gastrobronchial fistulas

\begin{tabular}{|c|c|c|c|c|c|c|}
\hline $\begin{array}{c}\text { Patient Number/ } \\
\text { Age }(\mathbf{y}) / \text { Sex }\end{array}$ & Disease & $\begin{array}{l}\text { Previous } \\
\text { treatment }\end{array}$ & $\begin{array}{l}\text { Location } \\
\text { of fistula }\end{array}$ & $\begin{array}{c}\text { Symptom } \\
\text { duration }\end{array}$ & $\begin{array}{l}\text { Follow-up } \\
\text { time (mo) }\end{array}$ & $\begin{array}{c}\text { Follow-up } \\
\text { result }\end{array}$ \\
\hline 1/64/M & Esophageal cancer & RT & LMB & $4 \mathrm{mo}$ & 9 & Live \\
\hline 2/58/M & Esophageal cancer & RT & RMB & $3 \mathrm{mo}$ & 4.8 & Dead \\
\hline 3/45/M & Esophageal cancer & RT & Trachea & $7 \mathrm{~d}$ & 7 & Dead \\
\hline 4/51/M & Esophageal cancer & RT & RMB & $15 \mathrm{~d}$ & 3 & Dead \\
\hline $5 / 69 / \mathrm{M}$ & Esophageal cancer & RT & RMB & $1.5 \mathrm{mo}$ & 4 & Live \\
\hline $6 / 52 / \mathrm{M}$ & Esophageal cancer & RT & LMB & $40 \mathrm{~d}$ & 3.2 & Dead \\
\hline 7/49/M & Esophageal cancer & $\mathrm{RT}$ and CTx & LMB & $17 \mathrm{~d}$ & 6 & Dead \\
\hline 8/57/M & Esophageal cancer & RT & RMB & $5 \mathrm{mo}$ & 15 & Live \\
\hline 9/73/M & Esophageal cancer & RT & LMB & $8 \mathrm{~d}$ & 8 & Dead \\
\hline $10 / 75 / \mathrm{M}$ & Esophageal cancer & RT & Trachea & $14 \mathrm{~d}$ & 6.7 & Live \\
\hline
\end{tabular}

$M$, Male; $R T$, radiation treatment; $L M B$, left main bronchus; $R M B$, right main bronchus; $C T x$, chemotherapy. 


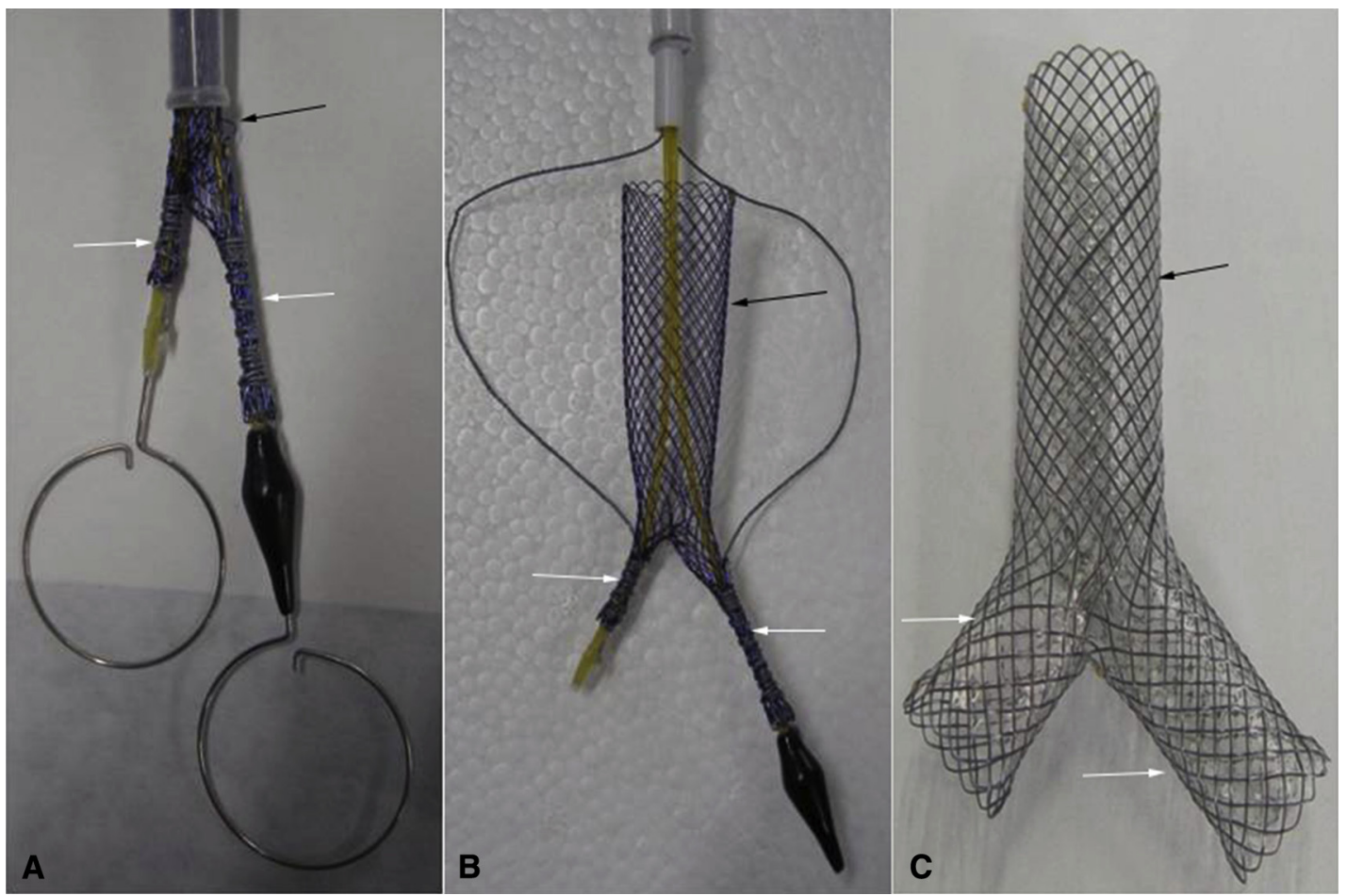

FIGURE 1. The appearance of the Y-shaped stent. A and B, Branched parts of a Y-shaped metallic stent (bundle mode, white arrows) and the main body (push mode, black arrow). C, Fully expanded Y-shaped stent comprising 2 branched parts (white arrows) and the main body (black arrow).

\section{Procedure}

We designed the Y-shaped stent-delivery system, which was manufactured by Micro-Tech Co. Ltd. (Nanjing, China). ${ }^{16}$ It combined the bundle mode and the push mode; the main body was inserted using the push mode, and the branched parts were inserted using the bundle mode (Figure 1, $A-C)$. The Y-shaped stents were implanted as previously reported. ${ }^{12,16,17}$ The implantation procedure is described in the following section (Figure 2, A-F; Figure 3, A-F).

After sedation, the patient was placed in a supine position on a digital subtraction angiography table, administered oxygen, and placed under electrocardiographic monitoring. A vacuum extractor was kept on standby for cleaning excreta out of the airway and mouth. The neck was elevated, and the head was extended and turned to the right (toward the physician) with a mouth gag in place. Under fluoroscopic guidance, a vertebral artery catheter (Cook Corporation, Bloomington, Ind, USA) was introduced over a hydrophilic guidewire (Cook Corporation) inserted through the mouth and trachea and into the diseased main bronchus. Contrast agent was injected through the catheter and the location and size of the fistula was shown (Figure 2, $A$ ). Then, the guidewire and catheter were inserted across the fistula to the distal end of one of the lobar bronchi (superior or inferior) of the diseased airway. Next, we sprayed 3 to $5 \mathrm{~mL}$ of $2 \%$ lidocaine through the catheter to achieve surface anesthesia. The guidewire was then changed to a stiff guidewire (Cook Corporation), which was fixed tightly in place. Another stiff guidewire was inserted into the distal end of the other lobar bronchus following the same procedure (Figure 2, B). Marks were made to recognize the 2 guidewires in the superior and inferior lobar bronchi, and the corresponding branched parts of the small Y-shaped stentdelivery system were introduced over the guidewires. The location of the small Y-shaped stent was adjusted to ensure that the branches were inserted into the corresponding lobar bronchi. The delivery system was fixed in place when the bifurcation of the stent made contact with the bifurcation of the main bronchus. The silk thread was withdrawn, and the branches of the small Y-shaped stent were deployed (Figure 2, C). The posterior handle was then fixed in place, and the anterior handle and sheath were pulled to deploy the main body at the site of the diseased main bronchus (Figure 2,D). One of the guidewires was kept in place, and another guidewire was inserted through the mouth into the healthy main bronchus. A large Y-shaped stent was implanted in the carinal region using a similar procedure and was adjusted so that it overlapped with the main body of the small Y-shaped stent. The length of the overlap was 1 to $3 \mathrm{~cm}$ (Figure 2,E). Catheters were inserted into the lumina of the stents, and radiography was performed to ensure that the fistula was sealed (Figure 2, $F$ ). After stenting, a bronchoscope was used to confirm the sealing of the fistula and to perform sputum suction, if necessary. Vital signs were monitored during the procedure. Symptoms such as dyspnea and changes in oxyhemoglobin saturation were observed. Sensitive antibiotics were selected according to the results of sputum bacterial cultures and administered to treat lung infection. Aerosol inhalation was used to promote expectoration drainage and alleviate any discomfort caused by the stent.

\section{RESULTS}

All the combined-type stents were successfully inserted at the first attempt. In total, 20 Y-shaped stents were inserted. Two of these stents did not fully expand during the procedure and were dilated with a balloon. No complications such as asphyxia, massive hemorrhage, and tracheal rupture occurred during the procedure. Both esophagography and airway radiography performed immediately after the procedure revealed no contrast leakage, and the fistula was fully sealed. Coughing during eating resolved after the stent insertion, and patients could tolerate a liquid or semiliquid diet well. In the 2 febrile patients, the body temperature returned to normal after the procedure. Three 


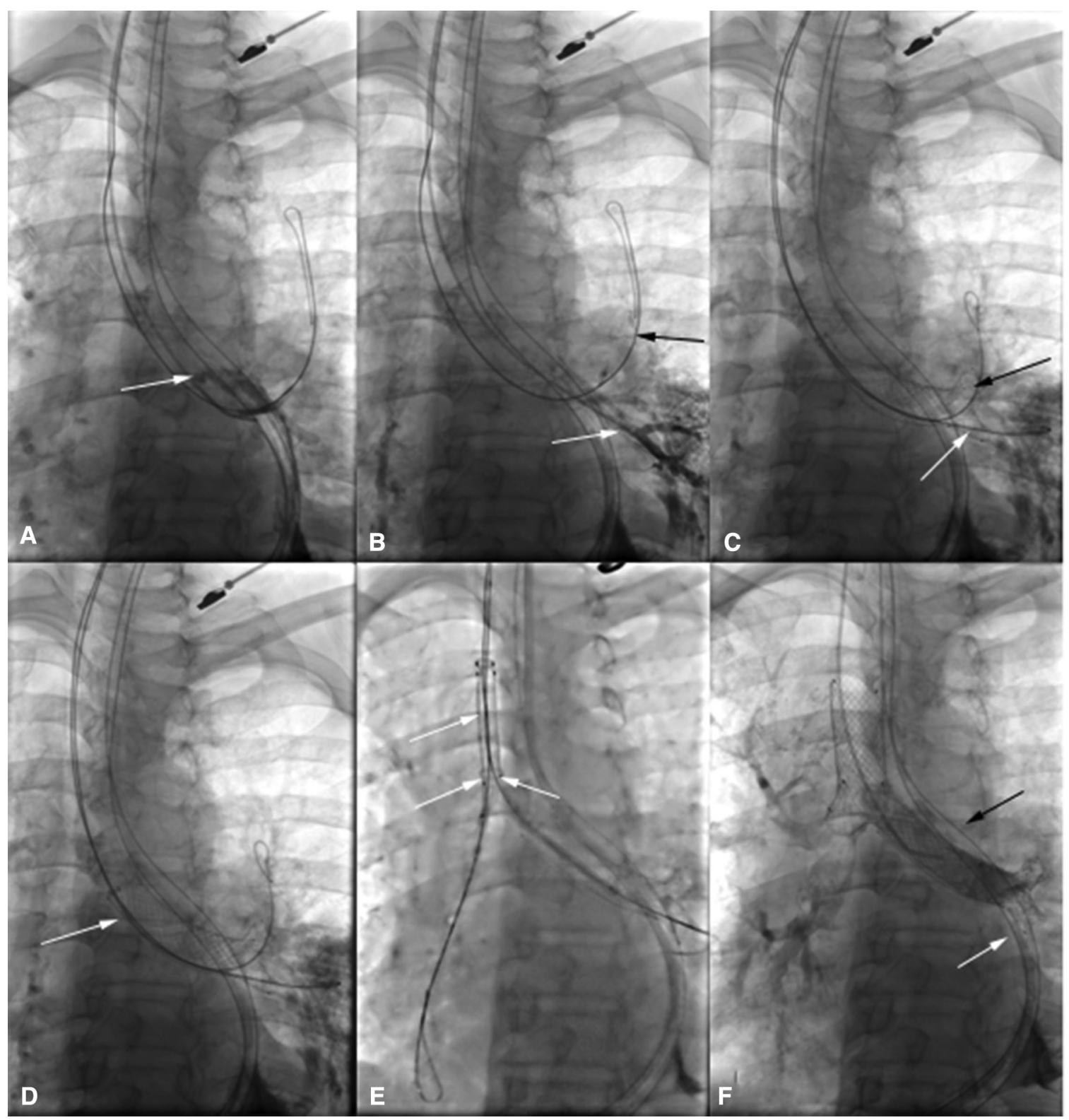

FIGURE 2. The treatment of a patient with gastrotracheal fistula (1 small Y-stent and 1 large Y-stent inserted). A, A 49-year-old man. During airway radiography, contrast agent from the left main bronchus passes through the fistula and enters the stomach (white arrow indicates the fistula). B, Guidewire and catheter in the left superior lobar bronchus (black arrow) and left inferior lobar bronchus (white arrow). C, A small Y-shaped stent is inserted (black and white arrows). D, The main body of the small Y-shaped stent is deployed (white arrow). E, A large Y-shaped stent (white arrows) is inserted and deployed at the carinal region. F, Airway radiography shows that the fistula is fully sealed. The white arrow indicates the gastrointestinal decompression tube. The black arrow indicates the enteral feeding tube.

patients had tolerable chest pain, which disappeared or was alleviated with analgesic therapy within 5 to 9 days.

After stenting, patients were discharged from the hospital after a median time of 14.2 days, and all of them were followed up through outpatient visits or telephone interviews once a month for 2 to 15 months. During followup, symptoms such as coughing when eating and drinking were monitored, and weight gain was recorded. In addition, upper gastrointestinal radiography was performed every 2 months to determine if a fistula was present. Bronchoscopy was performed to detect granulation tissue hyperplasia at the stent terminals, and if this was present, cryotherapy was conducted. If there was no coughing when eating and drinking, or if the patient could lie flat, the fistula was considered to still be sealed. If coughing when eating and drinking recurred, immediate 


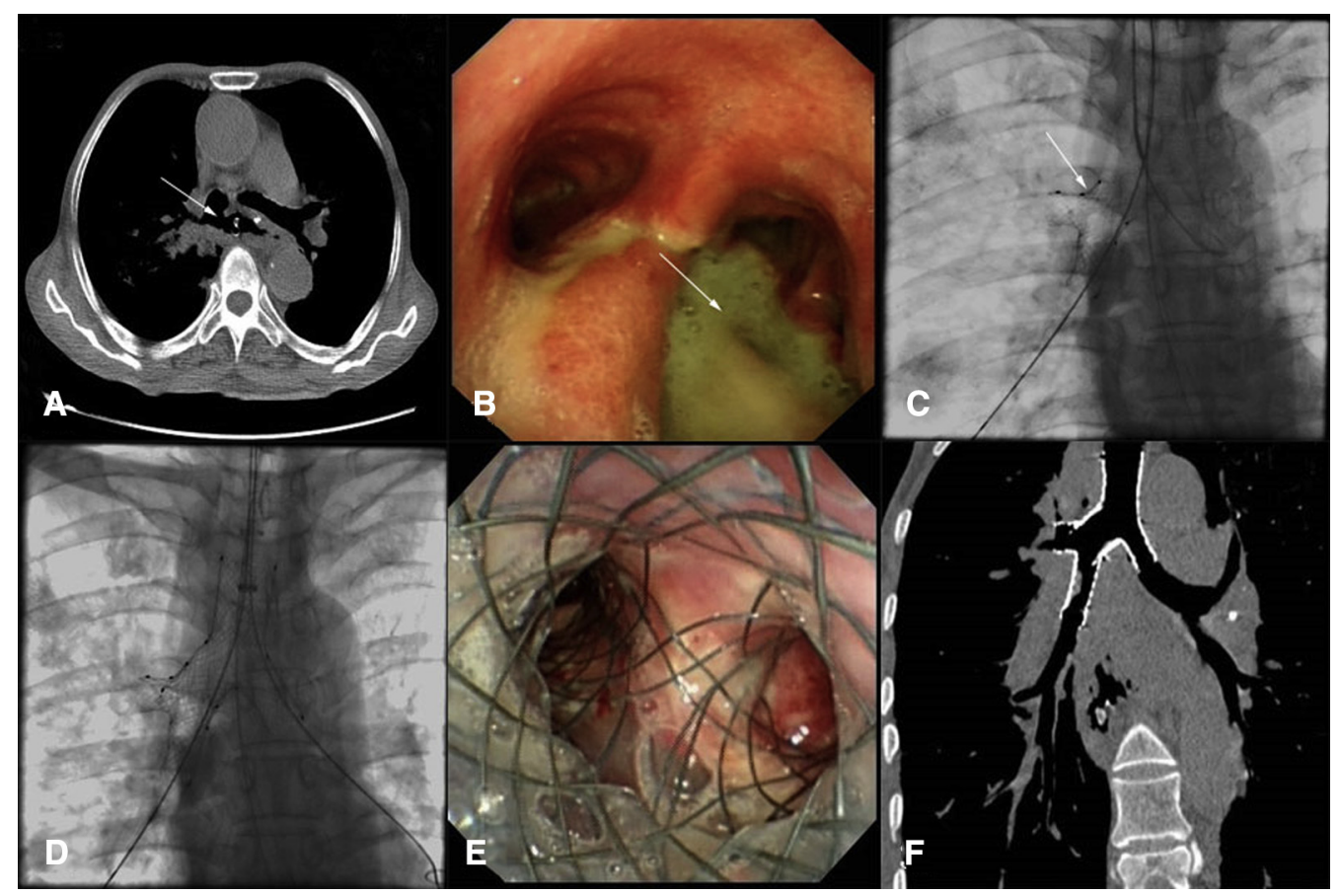

FIGURE 3. The treatment of a patient with gastrotracheal fistula (1 small Y-stent and 1 large Y-stent inserted). A, A 57-year-old man. Chest spiral computed tomography (SCT) before intervention shows a thoracic stomach-right bronchus fistula (arrow). B, The bronchoscopic features are in accordance with the SCT findings. A large amount of pus is seen covering the fistula surface. C and D, A small Y-stent is inserted in the diseased lobar bronchi (arrow), and a large Y-stent is inserted in the carinal region. E, Repeat bronchoscopy shows that the fistula is completely sealed and the airway is patent. F, Repeat chest SCT also shows that the fistula is well sealed.

chest SCT, upper gastrointestinal radiography, and bronchoscopy were performed; reintervention was conducted if a fistula was found.

The median survival after stenting in our patients was 7.1 months. Five patients died of tumor recurrence at 3.2, $4.8,6,7$, and 8 months after the procedure, but none of them had experienced any coughing during eating after the procedure. In 1 patient, a large amount of barium entered the airway through the fistula during upper gastrointestinal contrast examination before the intervention. This resulted in an intractable lung infection, and the patient died 2 months after the procedure. One patient had a thoracic stomachcarina-right main bronchus fistula and successfully underwent combined-type Y-shaped stent insertion. Coughing during eating was relieved postoperatively, and radiography showed good sealing. However, 4 months later, coughing during eating recurred, and radiography showed that the carinal fistula had enlarged and involved the left main bronchus. A small Y-shaped stent was inserted in the left main bronchus of this patient (Figure 4, A-F). Coughing during eating disappeared after the second procedure, and airway radiography and chest SCT showed good stent expansion, no dislocation, and full sealing of the fistula. This patient is still alive. The remaining 3 patients tolerated the stent well and had good palliation of their symptoms.

\section{DISCUSSION}

GTFs and GBFs are rare but life-threatening and challenging complications of esophagectomy for cancer. The literature on GTF after esophagectomy for cancer consists mainly of case reports. This entity is rare $(0.3 \%-0.5 \%)$ but potentially lethal. ${ }^{4}$ Conservative medical management, including antiinflammatory drug treatment, gastrointestinal decompression, and enteral nutrition, has unsatisfactory outcomes in patients with airway-gastric fistulas. Surgical repair of the fistula, which includes tracheal resection, lower lobectomy, or the creation of a muscle flap, may impose an excessive burden on a debilitated patient. ${ }^{5-7}$ Recent developments in interventional therapy have led to the increasing use of airway stents for the treatment of airway-gastric fistulas. However, in the early stages of the application of this therapy, the placement of a single or multiple L- or Y-shaped tubular stents was associated with a high dislocation rate; moreover, in the case of large fistulas, complete sealing was difficult to achieve, and thus, the clinical application of this intervention was limited..$^{9,10,18-22}$ The Y-shaped stent-delivery system was designed in our department, and in recent years, Y-shaped covered metallic stents $^{12,16,17}$ as well as Y-shaped silicone airway stents ${ }^{23-25}$ have been easily and widely used to treat severe carinal stenosis and airway fistulas, with good results. However, 


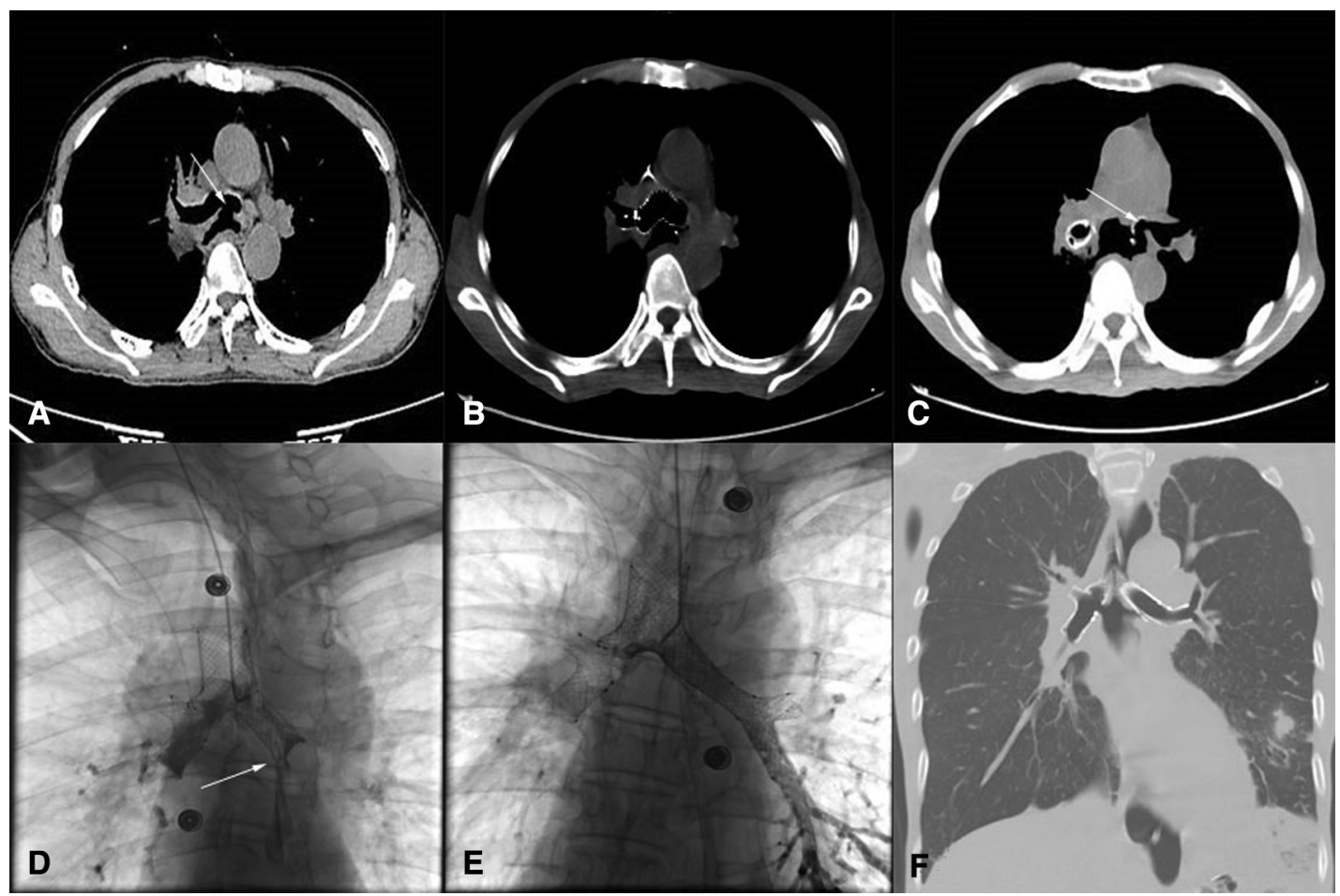

FIGURE 4. The treatment of a patient with gastrotracheal fistula (3 Y-stents inserted). A, A 69-year-old man. Chest spiral computed tomography (SCT) before intervention shows a thoracic stomach-carina-right main bronchus fistula. The arrow indicates the fistula located at the right bronchus, close to the carina. B, A large Y-stent combined with a small Y-stent is inserted, and repeat chest SCT shows full sealing. C, In this patient, coughing during eating recurred 4 months later. SCT now shows a new fistula under the left branch of the large Y-stent (arrow). D, Airway radiography confirms the new fistula (arrow). E, A small Y-stent is inserted in the left lobar bronchi, and the new fistula is fully sealed. F, Repeat SCT confirms the sealing of the fistula.

for complicated GTFs and GBFs involving the carina, main bronchi, or lobar bronchi, and for large fistulas involving the carinal region, a single small Y-shaped or even a large Yshaped stent could not fully seal the fistula. Although radiography performed immediately after stent insertion showed no contrast leakage, the symptoms of coughing during eating and infection would continue to worsen after the stenting procedure, leading to a poor quality of life. After full consideration, we chose the combined-type integrated Y-shaped self-expanding covered metallic stent (a large Y-shaped stent combined with a small Y-shaped stent).

The combined-type integrated Y-shaped self-expanding covered metallic stent not only covered the fistula but was also associated with lower rates of migration because it resembles the tracheal bifurcation and attaches to the main carina. ${ }^{12}$ When the metallic stent is in place, it can expand to fill the space between it and the mucosa. Its flexibility and radial force enable the stent to fit to the contours of the trachea or bronchus, making the stent well suited to prevent leakage of the luminal contents. ${ }^{26}$ Thus, the patients in this study tolerated the stent well and had good palliation of their symptoms, and there was no stent migration during the follow-up.
One complication of Y-shaped stents is the retention of secretions because the cilia cannot function when a covered metallic stent is in place. To avoid this, we provided sputum suction and administered continuous highconcentration oxygen during the procedure. Furthermore, the operation should be performed as rapidly and gently as possible to reduce irritation to the airway. After the procedure, adequate expectorants and antiasthma agents were administered intravenously. Terbutaline was administered through aerosol inhalation. Patients were encouraged to cough and expectorate by themselves, and phlegm suctioning was performed using fibroscopic bronchoscopy when necessary. Another complication of metallic Y-shaped stents is that they are not effective against neoplasms and proliferating granulation tissue. Therefore, surveillance bronchoscopies and debridement of granulation tissue were necessary to avoid stent obstruction. The prevention of these stent-related complications remains one of the major challenges of developing new stent designs.

The implantation of the combined-type Y-shaped integrated self-expanding covered metallic stent proved to be an effective, safe, and minimally invasive procedure for 
complex GTFs and GBFs. Patients tolerated the stent well and had good palliation of their symptoms.

\section{Limitations}

Because this was a retrospective study, there was no control group with which the baseline characteristics and the outcomes of the patients could be compared. In addition, because of the small sample size of this study, the evaluation of the long-term effects of the stent requires further followup and studies with larger sample sizes.

\section{Conflict of Interest Statement}

Authors have nothing to disclose with regard to commercial support.

\section{References}

1. Sahebazamani M, Rubio E, Boyd M. Airway gastric fistula after esophagectomy for esophageal cancer. Ann Thorac Surg. 2012;93:988-90.

2. Bakhos C, Alazemi S, Michaud G, DeCamp MM. Staged repair of benign tracheo-neo-esophageal fistula 12 years after esophagectomy for esophageal cancer. Ann Thorac Surg. 2010;90:e83-5.

3. Marty-Ané CH, Prudhome M, Fabre JM, Domergue J, Balmes M, Mary H. Tracheoesophagogastric anastomosis fistula: a rare complication of esophagectomy. Ann Thorac Surg. 1995;60:690-3.

4. Buskens CJ, Hulscher JB, Fockens P, Obertop H, van Lanschot JJ. Benign tracheo-neo-esophageal fistulas after subtotal esophagectomy. Ann Thorac Surg. 2001;72:221-4

5. Wang F, Yu H, Zhu MH, Li QP, Ge XX, Nie JJ, et al. Gastrotracheal fistula: treatment with a covered self-expanding Y-shaped metallic stent. World J Gastroenterol. 2015;21:1032-5.

6. Salahi H, Tahamtan M, Ziaian B, Masjedi M, Saadati Z, Hoseini N, et al. Gastrotracheal fistula as a result of transhiatal esophagectomy for esophageal cancer: an unusual complication. Case Rep Surg. 2015;2015:728393.

7. Reed MF, Mathisen DJ. Tracheoesophageal fistula. Chest Surg Clin North Am. 2003; 13:271-89.

8. Bennie MJ, Sabharwal T, Dussek J, Adam A. Bronchogastric fistula successfully treated with the insertion of a covered bronchial stent. Eur Radiol. 2003;13: 2222-5.

9. Lee P, Kupeli E, Mehta AC. Airway stents. Clin Chest Med. 2010;31:141-50.

10. Mitsuok M, Sakuragi T, Itoh T. Clinical benefits and complications of Dumon stent insertion for the treatment of severe central airway stenosis or airway fistula. Gen Thorac Cardiovasc Surg. 2007;55:275-80.
11. Kim JH, Shin JH, Song H, Choi CM, Shim TS. Esophagorespiratory fistula without stricture: palliative treatment with a barbed covered metallic stent in the central airway. J Vasc Interv Radiol. 2011;22:84-8.

12. Wu G, Li ZM, Han XW, Wang ZG, Lu HB, Zhu M, et al. Right bronchopleura fistula treated with a novel, Y-shaped, single-plugged, covered, metallic airway stent. Acta Radiol. 2013:54:656-60.

13. Raslan M, Gonzalez MC, Dias MC, Nascimento M, Castro M, Marques P, et al Comparison of nutritional risk screening tools for predicting clinical outcomes in hospitalized patients. Nutrition. 2010;26:721-6.

14. Velasco C, Garcia E, Rodriguez V, Frias L, Garriga R, Alvarez J, et al. Comparison of four nutritional screening tools to detect nutritional risk in hospitalized patients: a multicentre study. Eur J Clin Nutr. 2011;65:269-74.

15. Almeida AI, Correia M, Camilo M, Ravasco P. Nutritional risk screening in surgery: valid, feasible, easy! Clin Nutr. 2012;31:206-11.

16. Han XW, Wu G, Li YD, Zhang QX, Guan S, Ma N, et al. Overcoming the delivery limitation: results of an approach to implanting an integrated selfexpanding Y-shaped metallic stent in the carina. J Vasc Interv Radiol. 2008; 19:742-7.

17. Yang RM, Han XW, Wu G, Li YD, Li FB. Implantation of a self-expandable metallic inverted Y-stent to treat tracheobronchial stenosis in the carinal region: initial clinical experience. Clin Radiol. 2007:62:1223-8.

18. Agustsson T, Nilsson M, Henriksson G, Arnelo U, Juto JE, Lundell L. Treatment of postoperative esophagorespiratory fistulas with dual self-expanding metal stents. World J Surg. 2009;33:1224-8.

19. Hasan S, Beckly D, Rahamim J. Oesophagorespiratory fistulas as a complication of self-expanding metal oesophageal stents. Endoscopy. 2004;36:731-4.

20. Dutau H, Toutblanc B, Lamb C, Seijo L. Use of the Dumon Y-stent in the management of malignant disease involving the carina. Chest. 2004;126:951-8.

21. Monnier Y, Chollet-Rivier M, Gonzalez M, Nicod L, Simon C, Lovis A. Use of combined suspension laryngoscopy and jet ventilation for Y-shaped airway stents delivery. Ann Thorac Surg. 2014;97:2208-10.

22. Li YD, Li MH, Han XW, Wu G, Li WB. Gastrotracheal and gastrobronchial fistulas: management with covered expandable metallic stents. J Vasc Interv Radiol. 2006; 17:1649-56.

23. Machuzak MS, Santacruz JF, Jaber W, Gildea TR. Malignant tracheal mediastinal-parenchymal-pleural fistula after chemoradiation plus bevacizumab: management with a Y-silicone stent inside a metallic covered stent. J Bronchology Interv Pulmonol. 2015;22:85-9.

24. Murgu SD, Colt HG. Silicone Y stent placement at secondary left carina for malignant central airway obstruction. J Thorac Cardiovasc Surg. 2010;139:494-5.

25. Oki M, Saka H, Kitagawa C, Kogure Y. Silicone y-stent placement on the carina between bronchus to the right upper lobe and bronchus intermedius. Ann Thorac Surg. 2009;87:971-4.

26. Ross WA, Alkassab F, Lynch PM, Ayers GD, Ajani J, Lee JH, et al. Evolving role of self-expanding metal stents in the treatment of malignant dysphagia and fistulas. Gastrointest Endosc. 2007;65:70-6.

Key Words: Y-shaped stent, airway, fistula 